\title{
Green Development and Integrated Risk Governance
}

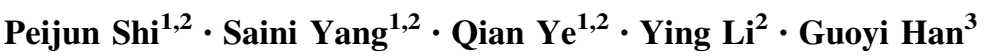

Published online: 26 June 2017

(c) The Author(s) 2017. This article is an open access publication

The "International Symposium on Integrated Governance of Large-scale Disaster and Economic Risks" was held in Qianhai, Shenzhen, China on 13-14 May 2017. The Academy of Disaster Reduction and Emergency Management of Ministry of Civil Affairs and Ministry of Education, Beijing Normal University, the Future EarthIntegrated Risk Governance Project, the Qianghai Financial Holdings, and the Qianhai Reinsurance cohosted the symposium. Beijing Normal University, the Qianhai Shenzhen-Hong Kong Modern Service Industry Cooperation Zone of Shenzhen, and the Global Risk Forum (GRFDavos) collaborated in the conference organization.

The major discussion themes for the symposium included global sustainability, green development, large-scale disaster, and integrated risk governance, which were pursued in a context of an increasingly interrelated hazard-risk environment. For much of the discussion, the Belt and Road Initiative was chosen as a departure point, in which risks as well as opportunities were explored from both the global and the Chinese perspectives.

Ying Li

ying.li@bnu.edu.cn

1 State Key Laboratory of Earth Surface Processes and Resource Ecology, Beijing Normal University, Beijing 100875, China

2 Academy of Disaster Reduction and Emergency Management, Faculty of Geographical Science, Beijing Normal University, Beijing 100875, China

3 Stockholm Environment Institute, 11523 Stockholm, Sweden
The symposium brought together over 100 participants from 25 nation states, United Nations agencies, civil society organizations, academia, and research groups. Also featured were over 50 speakers who ranged from senior government officials to technical experts, highlighted by the Head of the United Nations Office for Disaster Risk Reduction and the Special Representative of the UN Secretary General for Disaster Risk Reduction, and the Deputy Minister of the Ministry of Civil Affairs of China.

During the symposium, Beijing Normal University, the Qianhai Shenzhen-Hong Kong Modern Service Industry Cooperation Zone of Shenzhen, and the Global Risk Forum (GRF-Davos) signed a trilateral agreement that promised strategic collaboration to promote research, scientific knowledge, technology, and practical solutions on integrated risk governance, risk and disaster management, as well as on global climate change. The three parties will work together to promote regional and international conferences every other year in Shenzhen Qianhai and intermittently in Davos.

Highlighting the key insights and learning of the symposium, all participants adopted the Qianhai Consensus on Integrated Governance of Large-scale Disaster and Economic Risks, the full text of which is listed as an appendix below. The participants recognized that the capacity and extent of human impact on Earth's ecosystems have changed profoundly, and realized that human-induced climate change has already brought about notable adverse repercussions that impact society and economic development. With the continued growth of economic globalization, wide application of the internet, as well as the rapid progress of China's national strategy of the Belt and Road Initiative, green development and integrated risk governance have become primary concerns for most of the globe's countries. 
The consensus endorsed was based upon the themes outlined in this symposium. The themes were as follows:

1. Economic and Financial Risks in the Context of Globalization The globalization that is changing the world, brings in its wake both risks and opportunities. Traditional financial and public fiscal measures need innovation and new governance approaches are greatly needed to bring about fresh initiatives and the global collaboration to disseminate them.

2. Catastrophe Insurance and Reinsurance In the context of global change, insurance and reinsurance are applicable economic measures that support integrated risk governance. Economically disadvantaged communities may not offer attractive markets for private insurers, and governments may have to underwrite creative approaches to fill gaps in risk coverage. There are a great need for risk insurance and a promising and underdeveloped market that could be built up to provide a disaster insurance system in Asia.

3. Ecological Construction and Risk Prevention in the Belt and Road Initiative The Belt and Road region is facing multiple hazards. A joint, multinational ecological surveillance system would be very helpful to support the integrated monitoring and research required to build a harmonized ecological system.

4. Financial Risk Governance across the Belt and Road Region The Belt and Road Initiative is a mega project with complex subsystems. Modeling and simulation of the coupling effect of climate and economic changes are a key technology in coping with the risk of global change.

5. Assessment of Natural Disaster Risk in the Belt and Road Region The Belt and Road region is prone to multiple disaster risks, which are associated with major losses of life and capital. Drought, acidification, and sea level rise are the major hazards in this region. Integrated risk governance for large-scale disaster should be included in the research and development agenda of regional and international collaboration.

6. Earth Systemic Risk Management Disaster impact is usually transboundary. Collaborative, transnational research platforms will promote the multi-stakeholder participatory engagement and the modeling and implementation research that will make risk insurance a cost-effective reality.

7. Green Economy and Integrated Risk Governance of Large-scale Disaster Traditional economy often induced systemic risk. With the growth and development of economies, disaster losses are increasing as well. Green development is a paradigm shift and innovation that would transform the relationship between development and disaster risks, which values the harmonization of human society and nature, promotes inclusive and sustainable development, reduces systemic risks, and increases the resilience of social-ecological systems.

\section{Shenzhen Qianhai Consensus}

All participants from the International Symposium on Integrated Governance of Large-scale Disaster and Economic Risks, 14 May 2017.

1. We participated the International Symposium on Integrated Governance of Large-scale Disaster and Economic Risks, held 13-14 May 2017 in Shenzhen Qianhai, China. We share a common understanding that the capacity and extent of human impact on earth ecosystems have changed profoundly, human induced climate change has already brought about notable adverse repercussions on society and economic development. Moreover, with the continued development of economic globalization, wide application of the internet, as well as the rapid progress of China's national strategy of the Belt and Road Initiative, green development and disaster risk reduction have become primary concerns for most countries.

2. We recognize that when dealing with large-scale disasters and economic risks, regional and even global coping capacities are often insufficient to ensure social and economic stability. The complexities of largescale disasters and economic crises are likely to exacerbate global systemic risks in the future. The resulting casualties and property losses may well escalate if resilience in these systems is not increased.

3. We observe that effective global mechanisms for integrated systemic risk governance are often inadequate or lacking. In the context of increasingly interconnected, rapidly changing and uncertain political, economic, and social conditions, this implies an urgent and strong need for capacity and resilience building in coping with and managing global systemic risks across all levels and regions.

4. We acknowledge, from multiple perspectives, that global systemic risks challenge the entire human society. From a Chinese perspective, to constitute the community of common destiny for all mankind on the initiative of President $\mathrm{Xi}$ Jinping of China, and to construct an integrated risk governance system for national security and disasters management while enabling and securing sustainable development, there is a strong need to develop technological, social and economic systems resilient towards global systemic risks. Science and evidence based decision making is a key pillar to this resilient society. 
5. We pay close attention to the extensive applications of innovative research and development achievements, such as earth observation, human-environment system simulation, new information networks technologies etc., to strengthen the integrated risk governance of global systems. We also pay attention to marketoriented approaches in the integrated governance of large-scale disasters and economic risks. Such approaches may facilitate to mobilise resources for risk sharing through insurances, reinsurances, and financial products like bonds, large-scale disaster lotteries, etc. A broad range of instruments will be necessary to enhance the comprehensive coping capacity of human societies at local, national, regional and global scales.

6. We deeply apprehend the far-reaching differences among various cultures, histories, economies and societies on our globe. We also recognize that these differences offer great complementarity opportunities in tackling global systemic risks, from both theoretical and practical perspectives. For instance, the oriental philosophies of coping with disaster risks-illustrated by sayings like "Unity of Heaven and Man", "Evil Removal and Benefit Promotion", "Pursue Interests and Avoid Damages"—can be well integrated with many practices in modern western societies that values innovations of institutions, tools and products, and encourage the exploration of new financing instruments for integrated risk governance. Such mutual learning and integration can be an inspiration for important source of innovation and bring benefits to all.

7. We expect that the establishment of the Global Risk Forum Davos (Shenzhen Qianhai), will provide opportunities for new and high-level collaboration and exchange involving global experts and scholars, leading entrepreneurs and managers, as well as people from all relevant stakeholder groups. The resulting know-how and mutual trust can help preventing and mitigating global systemic risks by fostering resilient systems of business, cultural communication, social management, and ecosystem services security. We applaud the Shenzhen government for its foresight and vision; we support the ambition of developing Shenzhen Qianhai into a global hub for risk and finance industries.

8. We recommend that the Global Risk Forum Davos (Shenzhen Qianhai) focus on integrated systemic risk governance in an increasingly globalized world. From theory to technology, policy and practice, it should systematically promote and advance a broad exchange, learning and collaborative innovation of all actors. It should help bridging the gap between East and West in the common pursuit of integrated systemic risk governance and capacity development. The Forum shall encourage and support the initiation and development of relevant international science plans; emphasize data collection and monitoring; promote robust empirical research; closely follow critical and globally influential development strategies and initiatives such as the Belt and Road Initiative, as well as the global processes of implementing the Sendai Framework for Disaster Risk Reduction and the United Nations Sustainable Development Goals. Consequently, it shall, by means of adequate conference and research formats, discuss and promote-both in Shenzhen Qianhai and in Davos-the synergies among the regional consilience in disaster reduction, green growth and integrated risk governance in the context of sustainable development.

Open Access This article is distributed under the terms of the Creative Commons Attribution 4.0 International License (http://crea tivecommons.org/licenses/by/4.0/), which permits unrestricted use, distribution, and reproduction in any medium, provided you give appropriate credit to the original author(s) and the source, provide a link to the Creative Commons license, and indicate if changes were made. 